\title{
Knowledge and Awareness Regarding Corticosteroids and Effectiveness of a Novel Steroid Educational Module among People Visiting General OPD of a Tertiary Care Hospital
}

\author{
Yashashri C Shetty, Piyush Vinchurkar, Shraddha More, Abdullah Siddiqui, Shruti Tilak, \\ Saumitra Ginodia, Samyak Jinturkar, Vidhi Pancholi, Nritya Nair, Riya Goyal, Trushali Dongre
}

Department of Pharmacology and Therapeutics, Seth GSMC and KEM Hospital, Parel Mumbai, Maharashtra, INDIA.

\begin{abstract}
Introduction: In India, knowledge and awareness regarding prescription drugs is lacking. Of these, corticosteroids are one of the most widely used drugs and also one with an array of side effects. Therefore, discretionary use of these prevalent drugs must be emphasized to the general public. Thus, the present study was undertaken to determine knowledge and awareness regarding corticosteroids among people visiting the General OPD and evaluate the effectiveness of a novel steroid educational module. Materials and Methods: A cross sectional study was conducted in a total of 328 people visiting the General OPD after Ethics permission. After taking informed consent, a pre-validated questionnaire (CVR $=0.62-1, C V I=0.9$ ) was administered. 96 participants having low baseline knowledge regarding steroids from enrolled 328 participants were administered the module. Paired-t test was used for pre and post-interventional analysis. Results: Out of 328 participants, only $17.1 \%(56 / 328)$ knew about steroids. Of those, only $14 \%$ $(8 / 56)$ said that their source of information was doctor, $51.78 \%(29 / 56)$ didn't know any therapeutic use of steroids, and $71.5 \%(40 / 56)$ didn't know any side effects. The pretest score was 0/11 for all 96 participants, the post-test score was an average of 5.16. The $p$ value obtained was statistically significant $(0.0001)$. Knowledge regarding uses, side effects and formulations of steroids increased from 0 to $77.1 \%, 58.3 \%$ and $76 \%$ respectively. Conclusion: The knowledge and awareness of participants regarding steroids was negligent. In our study, Informative educational module used was observed to be very effective.
\end{abstract}

Key words: Steroids, Awareness, Knowledge, Outpatients, Educational module.

\section{INTRODUCTION}

Steroids are "Magic Bullets", a one stop panacea for almost all diseases. They are one of the most immensely popular drugs, both in India and worldwide, as is evident from their high sales numbers. ${ }^{1}$ The prevalence of use of topical steroids in a study conducted in Bangalore was as high as $61.2 \% .^{2}$ Over 25 lakh people in US were consuming oral steroids from the period of 1999-2008. ${ }^{3}$ The top prescribers of topical steroids in India, after dermatologists, are general practitioners, gynaecologists, paediatricians, and consulting physicians. ${ }^{1}$ Complications with chronic use of corticosteroids include a wide spectrum of side effects on almost all the systems from cardiovascular, musculoskeletal, digestive, endocrine, ophthalmic, skin, and neurological. Moreover even if the steroids are used for 30 days it increases the incidence of acute adverse events like sepsis, venous thromboembolism and fracture by two fold to five- fold above the background rates. ${ }^{4}$

Awareness among patients about the prescription drugs is very less. ${ }^{5}$ Most of
DOI: 10.5530/ijopp.15.1.8

Address for correspondence: Dr. Yashashri Shetty, $M D, D B M$,

Associate Professor, Department of Pharmacology and Therapeutics, Seth GSMC and KEM Hospital, Parel Mumbai-400012, Maharashtra, INDIA.

Email id: yashashrirajit@gmail. com

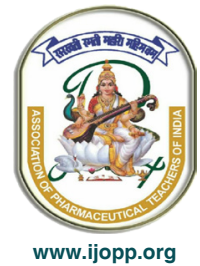


the patients are not aware about the indications, ${ }^{5}$ side effects, warnings of the drug they are consuming. ${ }^{6}$ The causes can be divided into healthcare professional related (increased workload, inadequate time and attention provided by healthcare professionals to patients) patient related (illiteracy of patients, lack of specialised labelling on medicines for illiterate patients) and system related factors(absence of pharmacists at the hospital). ${ }^{7}$ These factors have a great influence on patients knowledge and awareness about the drugs. Thus there is a urgent need of patient education.

The present study was undertaken to determine knowledge and awareness among patients and their relatives attending the General OPD regarding corticosteroids and to evaluate the impact of an informative module, concerning steroids, on their existing knowledge.

\section{MATERIALS AND METHODS}

The study was designed as a single-centre, questionnairebased, cross-sectional study conducted over a period of 8 months and was carried out after obtaining approval of the Institutional Ethics Committee (IEC2/ OUT/511/19).

The questionnaire was prepared under the guidance of the faculty from the Department of Pharmacology and Therapeutics. The questionnaire was validated by the members of faculty from the Department of Community Medicine, Dermatology, Pharmacology and General Medicine. Content Validity Ratio (CVR) was calculated and a value greater than or equal to 0.6 was considered valid. Questions with a CVR ratio ranging from $0.6-1$ were included in the questionnaire. The Content Validity Index was found to be 0.92 whereas the steroid educational module was validated by subject experts from department of Pharmacology, General Medicine. The informed consent document, questionnaires and the steroid educational module were prepared in English and translated into Hindi and Marathi, the most commonly used languages in the local population. Vernacular versions were back translated into English to prevent any discrepancy and to ensure quality and accuracy.

The total patient load of General OPD is approximately 3000 patients per month i.e. 36,000 patients per year. Hence, a sample size of 600 was deemed appropriate for this pilot study as per the guidelines for rational use of medicine [ref: World health Organisation. Guide to Good prescribing [Internet]. Geneva [cited 2019 May 23]. Available from https://apps.who.int/iris/bitstream/ handle/10665/59001/WHO_DAP_94.11.pdf

As per the inclusion criteria, patients and their companions visiting the General OPD in KEM hospital, aged between 18 and 65 years and able to read and write either English, Hindi or Marathi were invited to participate in the study during their wait in the OPD. Individuals who were unable or unwilling to consent were excluded from the study. People who agreed to participate in the study were administered a validated questionnaire, after taking their written informed consent. Confidentiality was maintained by coding all the filled questionnaires with unique identifiers. In all, there were 12 questions in the questionnaire other than demographic details which included age, gender, education, languages known etc. The questions were of 2 types Knowledge and awareness were the domains as depicted in Table 1.

One question in the questionnaire was to check the reaction of the patient to the situation when doctor prescribes steroid to him/her.

A written module containing information regarding the steroids, their indications, side effects and precautions to be taken while using them was made by the investigators with the help of Department of Pharmacology and Therapeutics, Dermatology and Medicine. The Module made a special emphasis on instructions to be followed while applying steroidal creams and ointments. 5-10 min was the time to administer the module. Later patient's feedback was taken post intervention. The responses were entered in MS excel of version 2016, analysed using SPSS version 23.0. The data was analysed using descriptive statistics and Chi square test was used to find association between demographics and knowledge and awareness regarding steroids. Pearson correlation was used to find correlation between steroidawareness with

Table 1: Type of questions.

Knowledge based questions

Do you know any use of steroids?

What are the forms in which steroids are available/ administered?

Anabolic steroids should be used for increasing muscle mass

Do you know any side effects of steroids?

Is steroid preparation available over the counter?
Awareness based questions

Have you heard about steroids?

What is your source of information for Steroids?

Did you use steroid anytime in last one year?

Have you advised anyone in your family to take steroids?

Have you been advised by anyone in your family to take steroids?

Do the doctors give information about effects and side effects of steroids? 
demographics. Paired $t$ test was used for pre and post interventional survey analysis. $P<0.05$ was considered statistically significant.

This study was conducted in compliance with all the applicable institutional ethical guidelines for the care and welfare of the participants.

\section{RESULTS}

A total of 600 individuals were screened out of which 328 agreed to participate in the study. The mean age of the participants was $35.75 \pm 12.48$ years. $61 \%$ (200/328) were males and 39\% (128/328) were females. $94.8 \%$ of the research participants were literate and the remaining $5.2 \%$ were illiterate and the distribution of educational qualifications is given in Table 2.

\begin{tabular}{|c|c|c|}
\hline $\begin{array}{l}\text { Educational } \\
\text { qualification }\end{array}$ & Number & $\begin{array}{c}\text { Percentage of total } \\
\text { sample }\end{array}$ \\
\hline Post graduate & 23 & $7.0 \%$ \\
\hline Graduate & 67 & $20.4 \%$ \\
\hline $\begin{array}{l}\text { Higher secondary } \\
\text { education }\end{array}$ & 81 & $24.7 \%$ \\
\hline Matriculate & 65 & $19.8 \%$ \\
\hline $\begin{array}{l}\text { Dropped out before } \\
\text { matriculation }\end{array}$ & 17 & $5.2 \%$ \\
\hline Illiterate & 17 & $5.2 \%$ \\
\hline
\end{tabular}

185 were employed, 133 were unemployed and 10 retired from their service. 219 participants were married, 106 unmarried and 3 divorced. 233 were non vegetarians and 95 were vegetarians.

Out of 328 participants, $82.9 \%(272 / 328)$ had never heard about steroid hence they were not able to answer any further questions. Only the remaining 17.1\% (56/328) who claimed that they had heard about steroids were asked to answer the subsequent questions.

When asked about the source from where they learnt about steroids, 30/56 (53\%) from mass media, 18/56 $(32 \%)$ from friends/family, $8 / 56(14 \%)$ answered that they acquired information from a doctor. Response to some of the further questions is given in Table 3.

$42 \%(24 / 56)$ participants knew more than one dosage form in which steroids are administered. The common dosage forms known by them were injectable and tablets. When asked their opinion on the statement 'Steroids should be used for increasing muscle mass', $68 \%$ of the participants disagreed, 16\% were neutral and 14\% participants were in agreement.

In response to the statement 'What will be your reaction if your doctor prescribes you a steroid?', $37.5 \%$ answered they would respond negatively, $34 \%$ positively and $23 \%$ would be neutral. 3 responders didn't answer the question.

$71.5 \%(40 / 56)$ of the responders did not know any side effects of steroids while among the $28.5 \%$ (16/56) who did, swelling of the face was the most common answer.

\section{Table 3: Response by the participants to the questionnaire.}

\begin{tabular}{|c|c|c|c|}
\hline \multirow[t]{2}{*}{ Sr no } & \multirow[t]{2}{*}{ Question Asked } & \multicolumn{2}{|r|}{ Response type $(n=56)$} \\
\hline & & No & Yes \\
\hline 1 & $\begin{array}{l}\text { Have you advised anyone in your family to take } \\
\text { steroids? }\end{array}$ & $53(94 \%)$ & $3(6 \%)$ \\
\hline $1 \mathrm{a}$ & If yes, State the condition. & & $2 / 3$ - Didn't remember $1 / 3$ - Skin disease \\
\hline 2 & $\begin{array}{l}\text { Have you been advised by anyone in your family to } \\
\text { take steroids? }\end{array}$ & $50(89 \%)$ & $6(11 \%)$ \\
\hline $2 a$ & If yes, state the condition. & & $\begin{array}{l}\text { 4/6 - Body building } 1 / 6 \text { - Eczema } \\
1 / 6 \text { - Didn't remember }\end{array}$ \\
\hline 3 & Have you use steroids anytime in the last one year? & $49(87.5 \%)$ & $7(12.5 \%)$ \\
\hline 4 & $\begin{array}{l}\text { Are steroidal preparations available over the counter? } \\
\text { (without a valid prescription) }\end{array}$ & $40(71.5 \%)$ & $16(28.5 \%)$ \\
\hline 5 & $\begin{array}{c}\text { Do the doctors give information about effects and side } \\
\text { effects of steroids? }\end{array}$ & $28(50 \%)$ & $28(50 \%)$ \\
\hline 6 & $\begin{array}{l}\text { Do you know any therapeutic uses of steroids? } \\
\text { If yes, what are they? }\end{array}$ & $29(51.78 \%)$ & $\begin{array}{c}27(48.22 \%) \\
12 / 27 \text { - Bodybuilding } \\
7 / 27 \text { - Skin disease } \\
\text { 4/27 - Anti allergic } \\
3 / 27 \text { - Joint pain } \\
\text { 1/27 - Eye disease }\end{array}$ \\
\hline
\end{tabular}




\begin{tabular}{|c|c|}
\hline $\begin{array}{l}\text { Questions on which pre } \\
\text { and post-interventional } \\
\text { assessment was done }\end{array}$ & Points allotted \\
\hline \multirow[t]{2}{*}{ Uses of steroids } & 1 point for every use listed \\
\hline & $\begin{array}{l}\text { Minimum } 2 \text { uses were } \\
\text { accepted }\end{array}$ \\
\hline \multirow[t]{3}{*}{ Side effects of steroids } & $\begin{array}{c}1 \text { point for every side effect } \\
\text { listed }\end{array}$ \\
\hline & $\begin{array}{l}\text { Minimum } 2 \text { topical and } 2 \\
\text { systemic side }\end{array}$ \\
\hline & effects were accepted \\
\hline $\begin{array}{l}\text { Formulations in which steroids } \\
\text { are pre scribed/available }\end{array}$ & $\begin{array}{c}1 \text { point for each formulation } \\
\text { listed }\end{array}$ \\
\hline
\end{tabular}

There was no association between age and steroid knowledge and awareness [ $p=0.63]$ but there was a significant association and a weak correlation between education [Pearson' $\mathrm{R}=0.165, \mathrm{p}<0.003$ ], gender [Pearson'R $=0.21, p<0.001]$, employment [Pearson' $\mathrm{R}=$ $-0.169, p<0.003]$, marital status $[p=0.001$, Pearson' $=$ $0.12, p<0.023]$ for knowledge and awareness regarding steroids.

A scoring system was devised for statistical analysis of the pre and post interventional survey.

The scoring system of items used in the questionnaire is as depicted in Table 4.

The pre-test score was 0 for all the 272 participants but only 96 agreed to participate in the intervention and to give their feedback post intervention. A pre-validated module giving information regarding steroids (their usage, side effects and precautions to be taken while using them) was administered to each participant in the OPD premises. The range of the obtained post test score was 2-11. Table 5 shows the enhancement in knowledge post-intervention. The $p$ value obtained was 0.001 and was considered statistically significant. Knowledge regarding uses of steroids increased from $0 / 96$ to 74/96 (77.1\%) with asthma, arthritis, conjunctivitis and vitiligo being the most common uses known, formulations from $0 / 96$ to $73 / 96(76 \%)$, and from those $73,57(78 \%)$ now knew about ointments and creams, $70(95 \%)$ knew about tablets as a dosage form for steroids. Knowledge regarding side effects of steroids increased from $0 / 96$ to 56/96 (58.33\%), participants now knew about at least 2 side effects, acne and thinning of skin being the most common in case of topical corticosteroid use, and weakness of bones, swelling on face in case of oral steroids.
Table 5: Pre and posttest comparison of scores of

participants.

\begin{tabular}{|c|c|c|c|}
\hline \multirow{2}{*}{$\begin{array}{c}\text { Questions } \\
\text { on } \\
\text { Knowledge } \\
\text { domain }\end{array}$} & \multicolumn{3}{|c|}{$\begin{array}{l}\text { No. Of participants having } \\
\text { knowledge }(n=96)\end{array}$} \\
\hline & $\begin{array}{c}\text { Before } \\
\text { the intervention }\end{array}$ & $\begin{array}{l}\text { After the } \\
\text { intervention }\end{array}$ & $P^{*}$ value \\
\hline $\begin{array}{l}\text { Uses of } \\
\text { steroids }\end{array}$ & 0 & 74/96 (77.1 \%) & 0.001 \\
\hline $\begin{array}{l}\text { side effects } \\
\text { of steroids }\end{array}$ & 0 & $56 / 96(58.33 \%)$ & 0.001 \\
\hline
\end{tabular}

${ }^{*} p$ value is statistically significant when paired $t$ test was applied.

\section{DISCUSSION}

The study intended to assess knowledge and awareness among patients and their companions visiting the General Out Patient Department (GOPD) regarding steroids, which are rampantly used in general medicine and across other specialties. Their knowledge and awareness was found to be bleak, but it can be improved by providing patients with information and spending time with them while prescribing steroids or by conducting workshops for them.

The majority of patients attending GOPD were predominantly middle-aged males of the working population who, due to stress in their daily lives, also fall ill and generally visit doctors promptly. As such there is a male preponderance in India as health seeking habits and preference is biased towards the male gender. Similar gender based findings are given by Y Natarajan in the study titled Health care and equity in India. ${ }^{8}$

Majority of the population were literate which is consistent with the education trends for urban locales as compared to rural areas. ' Literacy rates are higher in metro cities due to the greater availability of avenues for education.

$56 \%$ patients were employed, $66 \%$ were married and $71 \%$ were non vegetarians. The trend towards non vegetarian food is increasing because of the availability and cross culture exposure in metro cities. The prevalence of nonvegetarians have increased in general as per the statistics given by Sample Registration System Baseline survey $2014 .{ }^{10}$

$83 \%$ participants were not familiar with steroids and its related information. This may be attributed either to them never having been prescribed steroids in their life or the lack of explanation and instruction from physicians and pharmacists prescribing steroids. It may also be due 
to a general lack of awareness among patients of the nature or effects of prescribed medication. This dearth of knowledge led us to amend our protocol in order to educate the surveyed population regarding steroids. The knowledge increased suddenly which is seen in case for any educational module. ${ }^{11}$ The findings are similar to a study conducted in Bengaluru with the same methodology which also found immediate enhancement in knowledge.

When asked if they had ever been advised by their friends and family or had themselves advised anyone to use steroids for any cause, the majority of patients said that they had not. When asked if they were aware of any uses of steroids the most frequent answers were bodybuilding, skin disease, eye disease and allergies. They were most familiar with the tablet and injectable dosage forms of steroids. Side effects are the major limiting factor for the use of steroids but $71.5 \%$ of the patients surveyed were not aware of any. The poor knowledge of steroids among this study population is also corroborated by the findings of a study published in the Indian Journal of Dermatology conducted by Sheth NK on topical steroids. ${ }^{12}$

The role of doctors the prescribers and pharmacists the dispensers is very important in providing appropriate information regarding steroids. The patients' lack of awareness indicates the poor consultation practices followed in public health sector.

When enquired about did they advise their near ones or were advised by their near ones to use steroids, majority of participants were not doing so. They have used steroid very sporadically. About do doctors inform regarding steroids while prescribing, half of them were for it and half were against it. On an average, participants were not aware of steroids as homogenous to a study published in the Indian journal of dermatology conducted by Sheth NK on topical steroids. ${ }^{12}$ The uses which they answered included bodybuilding, skin disease, eye disorder and as antiallergic. Anabolic Steroids are used for muscle building and as performance enhancers but it has its own long-term consequences, and still some gymnasiums promote its use. Other indications are rightly told by participants as steroids are one of the drugs used as antiallergic, dermatology conditions and ophthalmological conditions. The common dosage forms known were Injectables and tablets. In Emergency setup injectables are used and tablets are used in routine practice. There was no association between age, but found weak correlation between education and gender with the awareness regarding steroid use. Males were better aware than females as the educational status and priorities in every sector are given more to males. Education usually improves the general awareness and that may be factor for this finding. Age usually does not dictate knowledge, many a times working groups or middle aged people are better aware than the extremes of age population. There was a negative correlation between employable status and awareness regarding steroids. This cannot be explained as employed people are usually knowledgeable as compared to not employed. Here it depicts even employed people were unaware regarding steroids.

The scoring system for the pre and post interventional survey was prepared by investigators, for every correct answer 1 point was awarded and no points for not answering or for wrong answer. The baseline score was shockingly low. However, their knowledge of the indications, side effects and dosage forms improved after administration of the module. Such an improvement is a common finding, but long term retention occurs only if repeated training is given. ${ }^{13}$ This would help patients in their routine drug use and also in disseminating this knowledge to others.

\section{CONCLUSION}

Our study revealed a dearth of knowledge and awareness of the participants regarding steroids. The educational module designed by us was observed to be effective at providing the people with basic information about this class of medications. The use of tools, such as this module, by healthcare professionals would facilitate the process of conveying prescription drug related information to their patients.

\section{Limitations}

1. The study was done on patients visiting the general OPD, so they may have or may not have used steroids which could be the reason that the knowledge and awareness was poor.

2. Retention of knowledge of the participants was not checked as it was one time contact (Cross sectional) study. So for long term retention of knowledge, ongoing educational module need to be planned.

3. The results of the study cannot be extrapolated to other OPDs such as those in which steroids are used on a regular basis.

4. Sample size was not calculated and many refused to participate. We cannot assume that the population who refused may also be unaware regarding steroids.

Indian Journal of Pharmacy Practice, Vol 15, Issue 1, Jan-Mar, 2022 


\section{ACKNOWLEDGEMENT}

The authors would like to thank all the participants of the research and Heads of department of Community medicine Dr. Gajanan Velhal, who is also the incharge of General OPD run in KEM hospital, Mumbai. We are thankful to all those people who are directly or indirectly responsible for completion of this work.

\section{CONFLICT OF INTEREST}

The authors declare that there is no conflict of interest.

\section{ABBREVIATIONS}

OPD: Outpatient department; GOPD: General Outpatient department; CVR: content validity ratio; CVI: Content validity index MS: Microsoft; SPSS: Statistical packages for social sciences.

\section{SUMMARY}

Steroids are one of the most widely used drugs worldwide. The present study was undertaken to determine knowledge and awareness about corticosteroids among patients and their relatives visiting the General OPD and to evaluate the impact of an informative module about steroids on their existing knowledge. Post questionnaire, an informative module about steroids, indications, side effects and precautions was administered to them. The data was analysed using descriptive statistics and Chi square test was used to find association between demographics and knowledge about steroids. Of the 328 participants, $82.9 \%$ had never heard about steroids and were unable to answer further questions. Only the remaining $17.1 \%$ who were aware of steroids were asked to answer the subsequent questions. $14 \%$ said that their source of information was a doctor, $51.78 \%$ didn't know any therapeutic use of steroids and $71.5 \%$ didn't know any side effects. The lack of awareness may be due to people never having been prescribed steroids or not having been informed that they were being prescribed or were using steroids. Side effects are the major limiting factor for steroid use, but $71.5 \%$ of those who were aware of steroids didn't know any of the side effects. On administration of an educational module about steroids, knowledge regarding uses, side effects and formulations increased from 0 to $77.1 \%, 58.3 \%$ and $76 \%$ respectively. Such modules may be used by health care professionals for conveying prescription drug related information to their patients.

\section{Informed consent}

Informed consent was taken from all the research participants in the language they understood

\section{AUTHOR CONTRIBUTIONS}

1. YC Shetty, Vinchurkar P, More S: conceived and designed the study

2. Siddiqui A, Ginodia S, Jinturkar S, Dongre T: collected the data of the research participants

3. Vinchurkar P, Tilak S, Pancholi V, Nair N, Goyal R: Performed the analysis and wrote the Paper.

\section{REFERENCES}

1. Verma SB. Sales, status, prescriptions and regulatory problems with topical steroids in India. Indian J Dermatol Venereol Leprol. 2014;80(3):201-3. doi: 10.4103/0378-6323.132246, PMID 24823396.

2. Nagesh TS, Akhilesh A. Topical steroid awareness and abuse: A prospective study among dermatology outpatients. Indian J Dermatol. 2016;61(6):618-21, doi: 10.4103/0019-5154.193666, PMID 27904178.

3. Overman RA, Yeh JY, Deal CL. Prevalence of oral glucocorticoid usage in the United States: A general population perspective. Arthritis Care Res (Hoboken). 2013;65(2):294-8. doi: 10.1002/acr.21796, PMID 22807233.

4. Waljee AK, Rogers MA, Lin P, Singal AG, Stein JD, Marks RM, et al. Short term use of oral corticosteroids and related harms among adults in the United States: Population based cohort study. BMJ. 2017;357:j1415. doi: 10.1136/bmj.j1415, PMID 28404617.

5. Oenning D, De Oliveira BV, Blatt CR. Patient awareness about drugs prescribed after medical appointment and prescription. Cien Saúde Colet. 2011;16(7):3277-83. doi: 10.1590/s1413-81232011000800027, PMID 21808915.

6. Singh J, Singh N, Kumar R, Bhandari V, Kaur N, Dureja S. Awareness about prescribed drugs among patients attending Out-patient departments. Int J Appl Basic Med Res. 2013;3(1):48-51. doi: 10.4103/2229-516X.112240, PMID 23776839.

7. Saqib A, Atif M, Ikram R, Riaz F, Abubakar M, Scahill S. Factors affecting patients' knowledge about dispensed medicines: A Qualitative study of healthcare professionals and patients in Pakistan. PLOS ONE. 2018;13(6):e0197482. doi: 10.1371/journal.pone.0197482, PMID 29856753.

8. Balarajan Y, Selvaraj S, Subramanian SV. Health care and equity in India. Lancet. 2011;377(9764):505-15. doi: 10.1016/S0140-6736(10)61894-6, PMID 21227492.

9. Literacy and education -MoSPI [cited Sep 16, 2020]. Available from:http://www. mospi.-. Available from: http://gov.in/sites/default/files/reports_and_publication/ statistical_publication/social_statis-tics/Chapter_3.pdf.

10. Union Government's Sample registration system Baseline survey 2014 released by the Registrar general of India.

11. Nwozichi CU, Ojewole FO, Farotimi AA, Ojediran TD. Effect of selfinstructional module on knowledge about ebola virus disease among Nigerian University students in Bengaluru, India. J Educ Health Promot. 2016;5:4. doi: 10.4103/2277-9531.184557, PMID 27512696.

12. Sheth NK, Nair PA. Topical steroids: Awareness and misuse among patients, pharmacists and general medical practitioner. Indian J Dermatol Venereol Leprol. 2021;87(1):54-9. doi: 10.4103/ijdvl.IJDVL_84_18, PMID 30971536.

13. Denny MC, Vahidy F, Vu KY, Sharrief AZ, Savitz SI. Video-based educational intervention associated with improved stroke literacy, self-efficacy, and patient satisfaction. PLOS ONE. 2017;12(3):e0171952. doi: 10.1371/journal. pone.0171952, PMID 28333925. 